\title{
O GOVERNO CASTELLO BRANCO E A FEDERAÇÃO DAS INDÚSTRIAS DO ESTADO DE SÃO PAULO: AS BASES DO “MILAGRE” (1964-1967)
}

\author{
THE CASTELLO BRANCO GOVERNMENT AND \\ FEDERATION OF INDUSTRIES OF THE STATE OF SÃO \\ PAULO: THE BASIS OF THE "BRAZILIAN MIRACLE" \\ (1964-1967)

\section{Rafael Moraes} \\ Universidade Estadual de Campinas, São Paulo, Brasil, moraes.economia@yahoo.com.br
}

\begin{abstract}
Resumo. O presente trabalho aborda as políticas econômicas do primeiro governo militar de Humberto de Alencar Castello Branco sob o ponto de vista do empresariado industrial paulista. Seu objetivo consiste em averiguar o papel desta classe na consolidação deste governo, bem como em seu relativo êxito em conter a crise pela qual passava a economia do país, possibilitando a retomada do desenvolvimento no período seguinte. Por meio desta análise foi possível constatar a fundamental importância do apoio empresarial, especialmente no que tange aos resultados obtidos pelo programa de contenção inflacionária, o Plano de Ação Estratégica do Governo.
\end{abstract}

Palavras chave: Empresariado industrial; desenvolvimento econômico; crise; Plano de Ação Estratégica do Governo.

Abstract. This paper discusses the economic policies of the first military government, Humberto de Alencar Castello Branco, from the viewpoint of the industrial businessmen São Paulo. Its goal is to investigate the role of this class in the consolidation of this government, as well as in its relative success in containing the crisis through which passed the country's economy, allowing the resumption of development in the next period. Through this analysis, we determined the fundamental importance of support from businessmen, especially in relation to the results obtained by the program to contain inflation, the Plano de Ação Estratégica do Governo.

Key words: Industrial businessmen; economic development; crisis; Plano de Ação Estratégica do Governo.

Artigo recebido: 20 de fevereiro de 2015. Artigo aceito: 1 de junho de 2015.

Am. Lat. Hist. Econ., mayo-agosto, 2016, pp. 64-90 | DOI: 10.18232/alhe.v23i2.709 


\section{INTRODUÇÃO}

$\mathrm{E}$ m 1 de abril de 1964, um golpe de Estado liderado pelas Forças Armadas Nacionais depõe o presidente João Goulart, abrindo as portas para o primeiro governo do regime militar, comandado pelo marechal do Exército Humberto de Alencar Castello Branco, que assume o país quinze dias após o golpe. O governo de Castello Branco se estende por três anos até ser substituído pela administração do general Arthur da Costa e Silva em 15 de março de 1967.

A situação econômica em que se encontra o país é de grave crise, expressa no tripé: inflação alta, déficits público e externo e estagnação do produto. Este quadro já se arrastava desde a breve gestão de Jânio Quadros, tendo apenas se aprofundado durante o governo Goulart (ver tabela 1).

A situação em que se encontrava o país no trágico fim do governo Goulart marcava o esgotamento de um modelo de desenvolvimento econômico que toma forma ao longo dos governos do presidente Getúlio Vargas (1950-1954), o nacional-desenvolvimentismo. O caminho tomado pelo Plano de Metas, capitaneado por Juscelino Kubitscheck, definiu outro modelo de desenvolvimento para o país, ainda com forte participação estatal, mas dentro dos limites impostos por um projeto industrial privado, que já se estruturava. A agonia do governo Goulart responde exatamente a este antagonismo de forças entre as hostes governamentais que defendiam um projeto estatal-reformista e de outro lado, o crescente poder industrial e seu ideário de desenvolvimento com viés privatista. Neste contexto, a defesa das reformas de base e a excessiva proximidade do então presidente com setores trabalhistas marcam sua dificuldade, senão impossibilidade, em contar com o apoio industrial em suas políticas de combate à crise.

Neste ínterim, o apoio civil, composto por grande parte da elite industrial do país, ao golpe de 1964 faz prevalecer o projeto desta classe, e o governo Castello Branco se inicia umbilicalmente ligado a este setor. Diante disto, o objetivo deste trabalho consiste em demonstrar, a partir da forte relação Estado-empresariado industrial, como o combate à crise e o início da retomada do desenvolvimento, que culminaria no milagre econômico em 1968, não pode ser explicado apenas a partir da análise das ações estatais, como parece privilegiar a literatura econômica tradicional. A relativização do papel do Estado, demarcando a importância de sua relação com a sociedade civil, mesmo em um governo ditatorial parece ser o mais frutífero e eficaz caminho para a total compreensão dos acontecimentos do período.

Para concretizar este objetivo, o método utilizado será o estudo do discurso dos industriais frente às ações do presidente. Postula-se aqui que tais discursos contenham em suas linhas e entrelinhas o posicionamento deste 


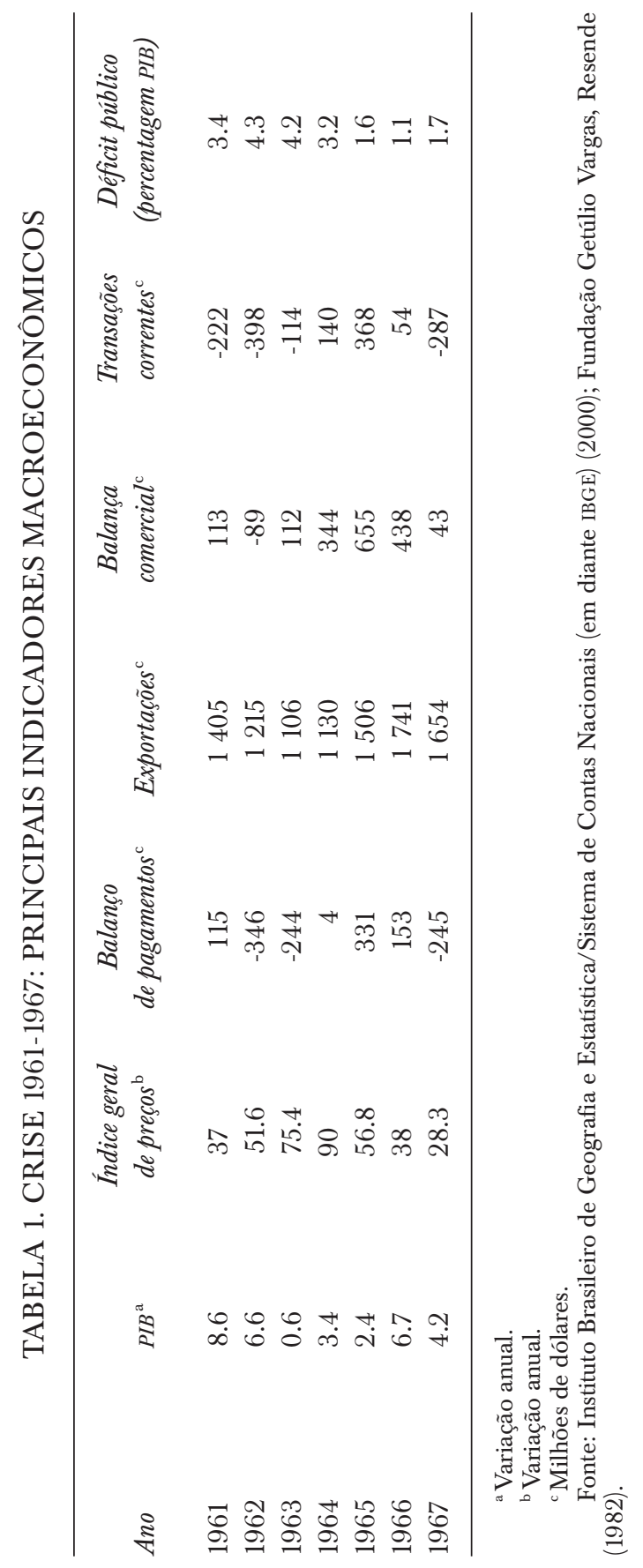


setor, contrário ou favorável a tais ações. Entende-se que os discursos mesmo quando não revelam o verdadeiro teor de uma ideologia, expressam uma visão com a qual quem o pronuncia deseja ver-se relacionado. Neste sentido, o discurso público do empresariado é aqui visto como uma forma de pressão, como um mecanismo de combate que visa a influenciar e/ou direcionar as ações seja do governo, seja de seus pares industriais.

Uma vez definidos os métodos, resta ser apontado o representante do pensamento industrial, fonte do material a ser averiguado. Neste caso, optou-se por uma entidade representativa da indústria. Tal escolha foi realizada com base na percepção do importante papel desempenhado por estas instituições como aglutinadoras dos industriais, que tiveram grande adesão às suas fileiras durante o período abordado. A entidade escolhida foi a Federação das Indústrias do Estado de São Paulo (em diante FIESP). A opção por esta instituição e não pela Confederação Nacional das Indústrias responde à existência de graves conflitos internos neste último órgão durante o período, o que levou a que o mesmo não fosse reconhecido por parcela significante do setor como representante de seus interesses de classe (Leopoldi, 2000). ${ }^{1}$ Em segundo lugar, a escolha da FIESP passa pela forte liderança da indústria paulista que, então, representava mais de $50 \%$ do parque industrial do país. Por fim, como fonte para os pronunciamentos, discursos, estudos e enunciados produzidos por esta entidade será utilizado o Boletim Informativo do Centro das Indústrias do Estado de São Paulo-Federação das Indústrias do Estado de São Paulo (em diante Boletim Informativo), publicado por esta organização e distribuído a todos os seus associados e a outros segmentos da sociedade civil, durante o período estudado. ${ }^{2}$ Em função complementar a análise do período, foi utilizado o Jornal do Brasil, um dos diários de maior circulação do período abordado, com a finalidade de encontrar posicionamentos públicos da entidade, de outros empresários e figuras de destaque com relação ao governo.

1 “Sob o governo Jânio Quadros, um grupo da FIESP (tendo à frente o industrial José Vilella de Andrade Jr.) se associou à FIRJ e demandou do presidente Quadros uma intervenção na Confederação Nacional das Indústrias. O ministro do Trabalho realizou então a primeira intervenção em toda a história da Confederação Nacional da Indústria e nomeou uma junta para dirigir a Confederação, da qual fazia parte Vilella de Andrade Jr. Esse foi o começo da decadência da Confederação Nacional das Indústrias. A entidade sofreu mais uma intervenção governamental quando mudou o governo em 1961, com a chegada de João Goulart à presidência. Em 1963-1964, a Confederação Nacional das Indústrias era praticamente a única associação empresarial que apoiava o presidente João Goulart. Por isso, quando adveio o golpe de 1964, a Confederação sofreu a terceira intervenção" (Leopoldi, 2000, p. 89).

${ }^{2}$ Distribuído para mais de 8400 estabelecimentos industriais do estado de São Paulo, além de outros 2000 exemplares remetidos a assinantes particulares e entidades industriais de outros estados e países. Dados apresentados em Boletim Informativo, 646, 1962, p. 210; CIESP-FIESP, [1961-1967]. 
Além desta introdução este trabalho encontra-se subdividido em duas seções, além das considerações finais. Na primeira seção são apresentadas as políticas econômicas do governo Castello Branco, em especial seu Plano de Ação Estratégica do Governo (em diante PAEG), visto pela literatura tradicional. Na segunda seção o mesmo recorte é apresentado, agora sob o ponto de vista do empresariado industrial paulista.

\section{A gestão Castello Branco: a FormaÇão do GOVERnO, SUAS DIRETRIZES, AÇÕES E RESULTADOS}

Na madrugada entre os dias 30 e 31 de março de 1964, contrariando planejamento prévio da cúpula das Forças Armadas Brasileiras, partiram de Juiz de Fora, em Minas Gerais, sob o comando do general Olympio Mourão Filho, tropas do Exército com o objetivo de derrubar o governo do então presidente João Belchior Marques Goulart. Hoje já é amplamente reconhecido que não foi a radicalização do governo Goulart, expressa no comício de 13 de março, a razão para o desencadeamento do golpe militar concretizado em primeiro de abril. Como vemos em Dreifuss (1981), a conspiração golpista iniciou-se quase que concomitantemente ao governo Goulart. Nesse mesmo estudo são apresentados documentos que comprovam a participação civil em torno da estruturação do golpe. A logística militar foi operada sob forte articulação da sociedade civil organizada. De forma que todo o aparato já havia sido organizado e os acontecimentos de março de 1964 foram apenas o rufar das caixas para o deflagrar da operação.

A frágil ou nula resistência do aparato militar legalista, aliada a perplexidade popular e a ação "pacifista" do presidente deposto, fez com que o golpe rapidamente se concretizasse sem derramamento de sangue. Em 15 de abril de 1964, o novo presidente já estava eleito e o novo governo constituído. Os resquícios da breve passagem de Goulart pelo poder foram facilmente eliminados por meio de cassações, prisões e exílios autônomos ou forçados de deputados, ministros e até governadores.

Superada a fase de "limpeza", coube ao novo governo, capitaneado pelo ex-chefe do Estado Maior do Exército, marechal Humberto de Alencar Castello Branco, alocar em sua administração os homens civis e militares empenhados na concretização do golpe ou simpáticos a ele. Cabia a estes representantes do pensamento conservador do país apresentar imediatamente as respostas à crise e os caminhos para a retomada do desenvolvimento "livres da demagogia e do populismo".

O Ministério constituído por Castello Branco foi considerado por muitos um ministério técnico, livre das pressões políticas que determinavam 
a formação dos gabinetes de presidentes civis (Viana Filho, 1975). Para Dreifuss (1981) estes "técnicos" constituíam, na verdade, a elite econômica e empresarial que havia se envolvido no processo de desestabilização do governo Goulart. Particularmente na área econômica, o governo Castello Branco contou com dois dos maiores expoentes do conservadorismo brasileiro, o "monetarista" e membro do Instituto de Pesquisas e Estudos Sociais, Roberto de Oliveira Campos e o "liberal" Octávio de Gouveia Bulhões. O primeiro ficou encarregado da área do Planejamento e o segundo da pasta da Fazenda.

Roberto Campos havia se notabilizado nos anos que antecederam ao golpe por sua postura crítica quanto às interpretações estruturalistas do processo inflacionário. A despeito de não poder ser considerado um monetarista em seu sentido pleno, podemos afirmar que Roberto Campos defendia o combate à inflação por meio de receitas notadamente originárias desta corrente teórica. Para o economista, a inflação brasileira era decorrente de erros e excessos do poder público, que gastava mal e além de sua capacidade de financiamento, o que o obrigava a financiar por mecanismos inflacionários seus sucessivos déficits fiscais. Desta forma, o combate à aceleração da inflação passava diretamente, segundo Campos, pelo corte de gastos públicos. Por outro lado, para Campos os aumentos de salários e a expansão desenfreada do crédito ao setor privado reforçavam a ciranda inflacionária.

Como vemos em Santos (2000), para Roberto Campos a marcha do desenvolvimento econômico permitia a tolerância de desajustes sociais. Em suas publicações o economista afirmava ser impossível cavalgar ao mesmo tempo os cavalos do desenvolvimento e da distribuição. Por esta razão, uma das duas frentes deveria ser priorizada. Assim, seria, nas palavras do autor, mais importante maximizar o progresso do que "repartir a pobreza". Desta interpretação o autor desenvolvia suas críticas ao que chamava política populista, que ao ampliar excessivamente os salários disparava a ciranda inflacionária, o que impedia a retomada do crescimento. Esta sua interpretação de um possível paradoxo "crescimento versus distribuição" estaria na raiz das políticas de combate à inflação, realizadas sob o governo Castello Branco (Santos, 2000).

Madi (1985) defende que há uma descontinuidade no pensamento de Campos, apresentando traços pré e pós-keynesiano. Neste sentido, perpassa o pensamento de Campos tanto a crítica ao estatismo e a politização das decisões de investimentos, quanto uma visão da importância da atuação do Estado num modelo "a la japonês" centralizando e coordenando investimentos fundamentais para o desenvolvimento. Defende por outro lado, uma absorção ilimitada de tecnologia importada, o que o posiciona 
em lado diametralmente oposto ao que qualifica como "nacionaleiros", os defensores de um "desenvolvimento nacional".

O novo ministro da Fazenda, Octávio Bulhões, por sua vez, caracterizou-se ao longo de sua história como um crítico ainda mais contumaz da intervenção estatal na economia, o que permitia que alguns analistas o qualificassem como neoliberal. O novo ministro da Fazenda havia sido um duro crítico da gestão Kubitschek, especialmente devido à construção de Brasília. Segundo Bulhões, realizar 50 anos em cinco acabaria redundando em 500\% de inflação. Para ele o desenvolvimento econômico devia responder aos incentivos privados e se orientar pelo sistema de preços relativos. A intervenção estatal demasiada visando a acelerar este processo acarretava em desequilíbrios inflacionários que no médio prazo provocariam desajustes e recessão. Por fim, Bulhões era enfático em sua defesa da livre entrada de capitais estrangeiros servindo como suporte ao desenvolvimento da indústria nacional (Saretta, 2001).

Segundo Lopreato (2011), por trás das ações levadas a cabo pela equipe econômica do governo Castello Branco encontravam-se diretrizes da síntese neoclássica da teoria keynesiana. Este arcabouço teórico é possível de ser identificado nos documentos que instauram o PAEG e as reformas estruturais, especialmente por meio do papel relevante atribuído ao Estado no processo de desenvolvimento, ainda que o combate à inflação seja preconizado sob moldes ortodoxos. "O Estado assumiu o papel de protetor da estabilidade e de defensor do crescimento, responsável por suprir as falhas de mercado e atuar em setores em que o volume inicial de capital e a questão tecnológica inviabilizavam a ação do setor privado" (Lopreato, 2011, p. 67). O PAEG neste sentido, apesar de voltado primordialmente para as questões conjunturais (inflação e balanço de pagamentos), tinha como objetivo estruturar o Estado para se posicionar como agente propulsionador do processo de desenvolvimento a longo prazo.

Em termos precisos, o PAEG apresentava a inflação brasileira como o resultado de um desajuste nos mecanismos de distribuição da renda nacional. De um lado o governo injetava na economia mais do que arrecadava por meio de seus constantes déficits, de outro, empresas e trabalhadores travavam uma luta constante em torno dos reajustes de salários e do aumento dos preços, resultando em uma espiral preços-salários que pressionava o nível da demanda monetária para cima. Martone (1975) apresenta uma síntese da interpretação da ciranda inflacionária realizada no PAEG. De acordo com a mesma, a aceleração da inflação se iniciava quando o governo emitia moeda para cobrir seus déficits. Como a oferta de bens não alcançava imediatamente o novo nível de demanda gerado pela expansão monetária, o reequilíbrio se fazia a um nível de preços mais alto. Este aumento de preços afetava o poder de compra dos assalariados, que 
passavam a pressionar por aumentos nos seus vencimentos. $\mathrm{O}$ aumento dos salários elevava os custos de produção, criando maior necessidade de capital de giro para as empresas. Ampliava-se assim a pressão para a expansão do crédito ao setor privado, o que dilatava ainda mais a oferta de meios de pagamentos e o nível de preços. Em outras palavras, Hermann (2005) afirma que, para o PAEG, os déficits alimentavam a expansão dos meios de pagamento que, por sua vez, sancionavam os aumentos de salário, e consequentemente dos preços.

Contribuía pesadamente para esta ciranda a restrição externa imposta pela tendência ao déficit no balanço de pagamentos. O que para Roberto Campos devia-se em grande medida aos desincentivos ao setor exportador da política cambial, quanto, e especialmente, ao viés ideológico "nacionaleiro" expresso dentre outras ações nos debates e posteriormente na lei de controle das remessas de lucros. Este posicionamento de aparente aversão aos capitais externos, segundo o então ministro, afastava novas inversões privadas e ainda criava restrições oficiais e extraoficiais à entrada de recursos por meio de empréstimos de agências multilaterais (Santos, 2000).

Neste arcabouço é que se enquadra o Plano de Ação Estratégica do Governo (PAEG) apresentado ainda em 1964. Seus principais objetivos consistiam no controle gradual da inflação, possibilitando a rápida aceleração do crescimento da economia, além da reversão da tendência a déficits no balanço de pagamentos que estrangulava a capacidade de importar (Brasil, 1964). De forma alinhada ao plano, uma série de reformas era prevista para reestruturar a economia diante de seu novo estágio de desenvolvimento. Neste quadro destacaram-se as reformas tributária, financeira, trabalhista e agrária. Tais reformas tinham por objetivos principais sanear as contas públicas por meio da elevação tributária e da criação de um mercado de dívida pública e construir um aparato institucional para o sistema financeiro de forma a criar um mercado de financiamento de longo prazo privado e um mercado de capitais no modelo estadunidense. No caso da política trabalhista e agrária, sua conotação nitidamente conservadora colocava as ações concretas no caminho inverso ao defendido no governo anterior. No primeiro caso a tônica foi a contenção dos reajustes salarias, centralizando seu controle nas mãos do Estado. No caso do setor agrícola, o objetivo maior da reforma consistia na industrialização do campo, como forma de elevar sua produtividade (Dreifuss, 1981).

Tendo em vista estas diretrizes, dentre as principais ações do período podemos destacar a criação do Banco Central do Brasil, de forma a atuar como banco emissor e responsável pela política monetária, substituindo a Superintendência da Moeda e do Crédito. De forma a possibilitar a criação de um mercado para a dívida pública foram instauradas as Obrigações Reajustáveis do Tesouro Nacional, que correspondiam a títulos indexa- 
dos a uma taxa de correção monetária, o que possibilitava ganhos reais a seus detentores. Através deste mecanismo o governo pode financiar, já em 1966, 100\% de seu déficit corrente através da colocação de títulos públicos no mercado (Lucinda e Arvate, 2005).

A reforma tributária realizada pelo governo teve como caraterísticas o aumento da carga de tributos e sua maior centralização na união. Segundo Sochaczewski (1993, p. 238), o governo, após estas modificações na área tributária, ampliou suas receitas em 3 por cento.

As mudanças na área trabalhista, por sua vez, não podem ser entendidas sem a menção ao drástico e acelerado processo de intervenção, prisão e extermínio de lideranças sindicais e sindicatos de forma a trazer para o interior do Estado os critérios para ajustes e revisões salariais (Dreifuss, 1981; Resende, 1990). Por sua vez, a estabilidade no emprego foi substituída pelo Fundo de Garantia por Tempo de Serviço, que passou a se constituir em um funding para os programas de habitação do governo federal. $\mathrm{O}$ resultado foi uma rápida redução nos salários reais, e forte aumento da desigualdade da distribuição de renda (Baer, 1996; Colistete, 2009; Hoffmann, 1978; Sochaczewski, 1993).

Por fim, de maneira a equacionar o problema externo propunha-se a diversificação das exportações, a consolidação da dívida externa, a restauração do crédito no exterior e o estímulo ao ingresso de capitais externos. Para tanto foram revogados os limites impostos pela lei de Remessa de Lucros decretada ainda no governo Goulart (Santos, 2000).

Os resultados do PAEG começam a ser sentidos, na medida em que os déficits dos governos, como proporção do PIB, entram em rota de redução, passando de 4.2\% em 1963 para 3.2\% em 1964, 1.6\% em 1965 e 1.1\% em 1966. Para esta redução dos déficits públicos foi de fundamental importância a elevação de impostos, o que fez a carga tributária saltar de $16 \%$ do PIB em 1963, para 21\% em 1967. Além disso, em 1965, 55\% deste déficit já era financiado com a emissão de títulos, enquanto em 1960 este era quase que integralmente financiado com a emissão de papel moeda (Resende, 1990). Ainda de acordo com Resende (1990), das três normas básicas do PAEG, a contenção dos déficits públicos foi a mais bem-sucedida. Como visto em Martone (1975) e Hermann (2005), a outra frente duramente combatida pelo PAEG, foi a questão salarial.

Outro dado relevante reside na considerável redução da inflação medida pelo índice geral de preços, calculado pela Fundação Getúlio Vargas para $28.4 \%$ em 1967, valor ainda alto, mas muito menor que os $90.5 \%$ de 1964. As transações correntes, após três anos de superávits, voltaram a ser deficitárias em 1967, sendo todo o déficit, todavia, financiado com o grande aporte de empréstimos e capitais autônomos internacionais efetivados após a instalação do novo governo. As contas públicas, como apresentado 
anteriormente, foram mais bem ajustadas, tendo o déficit da união reduzido de 3.2\% do PIB em 1964, para 1.7\% em 1967. O PIB que havia crescido $0.6 \%$ em 1963, expandiu-se em 3.4\%, 2.4\% e 6.7\%, nos três anos seguintes (IBGE, 2000).

Analisando os resultados das políticas do período, Hermann (2005) mostra que a política de contração do crédito ao setor privado foi bem menos rígida, mesclando fases de contração com outras de relaxamento dos controles creditícios. As metas de expansão do crédito foram ultrapassadas nos três anos do PAEG. Para este autor, o PAEG estabeleceu uma seleção dos custos que deveriam ser comprimidos para conter o processo inflacionário, e daqueles que deveriam ser preservados. Entre os primeiros encontravam-se os salários, e dentre os últimos, as tarifas das empresas estatais e os rendimentos reais do setor financeiro e dos rentistas em geral, protegidos pela correção monetária dos ativos e contratos. Esta "escolha", é nítido, não tem como fundamento uma decisão neutra ou de caráter técnico, mas certamente reflete o agrupamento de forças que sustentava o governo militar, em outras palavras, ela representa a forte sintonia entre o governo e o empresariado local. Sintonia esta que é matizada na relação de via dupla estabelecida entre frações dominantes do empresariado e a recém instalada burocracia estatal. É sobre este dinâmico e intrincado bloco de poderes que se estabeleceu a política econômica do período, e não, como parece sugerir parte relevante da literatura econômica do período, única e simplesmente, das hostes burocráticas do governo.

Desta forma, abre-se uma lacuna na avaliação do governo Castello Branco e de seu plano econômico, o PAEG, que enredará a próxima seção deste trabalho. Para tanto, objetiva-se relacionar o debate acerca da relativização do Estado frente ao projeto do empresariado, com os acontecimentos do período 1961-1967. Consideramos este período um divisor de águas na evolução da economia nacional por comportar o momento de definição do projeto de desenvolvimento nacional, que o país seguiria em seus próximos anos. Segundo Moraes (2012), grande parte da classe empresarial já tinha clara a sua posição quanto ao projeto reformista-trabalhista do presidente Goulart. Acreditamos ser simplista, portanto, aceitar que a relação do governo com esta classe não tenha tido papel decisivo na explicação das dificuldades deste governante em conter a crise. Da mesma forma, o fato de sabermos ter esta parte do empresariado se envolvido diretamente no golpe que deu posse ao governo seguinte, não nos permite acreditar que as relações entre ambos não surtissem efeitos nos desdobramentos das políticas econômicas de então. De posse de rico material de propaganda ideológica e expressão de ideias da FIESP, na seção seguinte serão apresentadas possíveis marcas desta atuação. 
A Federação das Indústrias do Estado de São Paulo-Centro DAS INDÚSTRIAS DO ESTADO DE SÃo PAUlO E AS POLÍTICAS ECONÔMICAS DO GOVERNo CASTELLO BRANCO

A indústria brasileira passou por grande salto de realização a partir dos anos 1930, chegando a 1964 como responsável por 33.7\% do PIB nacional (IPEADATA, 2015). Este crescimento esteve concentrado em grande medida no estado de São Paulo, e mais precisamente no entorno de sua capital homônima. ${ }^{3}$ Segundo dados da Pesquisa Industrial Anual de 1966, realizada pelo IBGE, a indústria paulista era responsável por $57 \%$ do valor da produção industrial do país (IBGE, 2015).

A importância econômica do parque industrial paulista também se reflete no prestígio político de suas entidades representativas ao longo da história (Bianchi, 2010; Leopoldi, 2000). Ao menos até o final dos anos 1960, a representação da indústria no estado esteve especialmente a cargo do Centro das Indústrias do Estado de São Paulo (em diante CIESP) e da Federação das Indústrias do Estado de São Paulo (FIESP), entidades que apesar de distintas em suas origens atuaram de maneira conjunta ao longo de praticamente toda a sua história. O CIESP surgiu em 1928 como desmembramento da Clube Comercial de São Paulo, tendo como principais lideranças, os empresários Jorge Street, Francisco Matarazzo e Roberto Simonsen. Este último, futuro presidente da agremiação, seria a principal liderança da indústria nas décadas seguintes. Em 1931, diante da reformulação e oficialização das entidades sindicais realizadas pelo governo Vargas, o CIESP tem seu nome alterado para FIESP. Apenas em 1943 um novo centro das indústrias seria fundado, tendo até o final da década estrutura e diretoria distintas (Bianchi, 2010; Leopoldi, 2000).

Segundo Leopoldi, problemas políticos e baixa representatividade econômica vão reduzindo o poder político das entidades menores e inclusive da Confederação Nacional das Indústrias, que em tese deveria ser a representante maior da indústria brasileira. No caso da Confederação Nacional das Indústrias, a questão segundo a autora ocorria devido ao fato do peso eleitoral dos estados não corresponder a sua importância econômica, o que privilegiava entidades do norte e nordeste na escolha das lideranças nacionais. Como elemento de seu descredito, Leopoldi cita as sucessivas intervenções governamentais na entidade, como a ocorrida em 1964, logo após o golpe a pedido da própria FIESP. O resultado desta articulação de fatos é que a entidade paulista amplia sua posição de representante da

\footnotetext{
${ }^{3}$ Para entender as razões da concentração indústria e São Paulo ver em especial Dean (1991) e Cano (1981).
} 
indústria nacional, sobrepondo-se inclusive ao órgão nacional (Leopoldi, 2000).

É de se esperar, a despeito de sua relevância econômica e mesmo de sua representatividade política que a FIESP, ao longo de sua atuação tenha apresentado postura condizente com sua condição regional, atuando muitas vezes em detrimento de interesses de outros segmentos industriais. É possível, entretanto, relativizar a significância destas prováveis divergências, no caso em tela, uma vez que para os objetivos do presente trabalho, o ponto fulcral da ação empresarial a ser analisado consiste em sua proximidade ou distanciamento ideológico diante do governo em questão. Tal fato decorre de que aqui considera-se a atuação empresarial sob dois ângulos: o primeiro sendo a incorporação de seus interesses na formulação das políticas públicas e o segundo sua reação majoritária, diante destas políticas, visto que aqui postula-se que se alinhados a elas o empresariado pode ter contribuído fortemente para seu sucesso. Em outras palavras, considera-se aqui que o peso político e econômico do empresariado paulista é suficiente para que suas ações e reações promovam efeitos significativos tanto na formatação quanto no grau de êxito das ações estatais.

Diante do grave contexto de crise que se colocou sobre o país a partir de meados da década de 1960, a FIESP-CIESP desempenhou seu papel de assessorar seus associados e refletir suas opiniões acerca dos desdobramentos desta crise. De forma a consubstanciar suas ideias, teses e políticas para o enfrentamento da mesma, as entidades utilizaram-se não apenas do conhecimento prático do singular grupo de empresários que compunha sua diretoria, como também de técnicos -economistas e juristas, entre outros- que realizaram estudos e pareceres sob encomenda. A publicação semanal de ampla divulgação entre industriais, ${ }^{4}$ Boletim Informativo, cumpriu a função de condensar e disseminar estes estudos e interpretações a respeito dos acontecimentos pertinentes à indústria nacional. Neste boletim encontramos as opiniões dos industriais acerca de praticamente todos os acontecimentos do período atinentes à indústria, ou que sobre ela produzissem efeitos.

Por meio de suas publicações e estudos, podemos perceber que, para a indústria de um modo geral, o processo inflacionário havia desempenhado importante papel durante os anos 1950. Como demonstra Saretta (2010) em trabalho sobre a reação da Confederação Nacional das Indústrias ao Programa de Estabilização Monetária de Kubitscheck, de modo geral o empresariado convivia bem com a inflação, pois acreditava que ao gerar

\footnotetext{
${ }^{4}$ Distribuído para mais de 8400 estabelecimentos industriais do estado de São Paulo, além de outros dois mil exemplares remetidos a assinantes particulares e entidades industriais de outros estados e países (Boletim Informativo, 646, 1962, p. 210).
} 
uma defasagem dos salários em relação aos lucros, o processo inflacionário criava uma "poupança forçada" crucial para financiar novos investimentos. Já no início da década de 1960, entretanto, o descontrole da aceleração de preços passava a produzir mais desequilíbrios que benefícios e tornava-se impossível, ou ao menos prejudicial, conviver com a inflação. A FIESP-CIESP, desta forma adota a política de apoiar medidas de contenção inflacionária. Todavia, não quaisquer medidas. Estas entidades desenvolvem e apresentam uma interpretação do descontrole inflacionário que se encaixa entre as interpretações estruturalistas e as monetaristas clássicas. Para estas entidades, e de certo modo para a indústria em geral, a inflação possuía características de uma inflação de demanda, fruto dos desajustes da rápida expansão industrial capitaneada pelo Estado. Entretanto, este não era o principal foco originário da inflação. As principais fontes causadoras da inflação seriam os déficits públicos e a política salarial dos governos.

No caso dos déficits, os industriais paulistas consideravam consequência de más políticas públicas e não fruto do excesso de investimento e financiamento públicos. Em sua publicação, Boletim Informativo, eles defendiam que o déficit orçamentário era consequência especialmente de cinco fatores: "excesso de funcionalismo público; má distribuição de investimentos em obras públicas; déficit de autarquias e empresas governamentais; deficiência do organismo arrecadador de tributos e despesas com viagens de turismo e com funcionários no Exterior" (Boletim Informativo, 634, 1961, p. 111).

Por sua vez, a política salarial cumpria o papel de pressionar os custos elevando assim os preços industriais. Como se lê no discurso do presidente da FIESP-CIESP, Rafael Noschese, publicado em seu boletim semanal: "Outro aspecto que não pode ser esquecido, no combate à inflação, é o de manter os aumentos salariais dentro dos limites de elevação do custo de vida. Qualquer política que vise abrandar a espiral inflacionária ficará comprometida, se as elevações salariais se processarem de forma imoderada" (Boletim Informativo, 679, 1962, p. 528).

Durante os anos em que o país foi governado por João Goulart, tanto sob o parlamentarismo como após o retorno do regime presidencialista, não faltaram nas páginas do Boletim Informativo referências aos equívocos governamentais que alimentavam a ciranda inflacionária, que se pretendia combater. Para estas entidades, os problemas advindos da administração pública originavam uma complexa rede viciosa que se encontrava na raiz do tripé representativo da crise. Desta forma, para a FIESP-CIESP as mesmas ações -ou omissões- que impediam o controle e aceleravam o processo inflacionário contribuíam também para a estagnação da economia e de certa forma para a crise externa. Moraes (2012) apresenta a conturbada relação entre o empresariado industrial e a administração Goulart, que 
após sucessivas tentativas de aproximação culmina na completa oposição daqueles ao presidente em exercício.

Neste contexto, faz-se necessário que antes de analisarmos diretamente a relação da FIESP-CIESP com o governo Castello Branco, façamos uma breve visualização da atuação nada imparcial desta entidade de classe nos acontecimentos que culminaram na queda de Goulart e na ascensão deste novo presidente. Para estas entidades, o golpe perpetrado pelas Forças Armadas foi considerado uma revolução, a impedir a continuidade do projeto "reformista-socialista" de Goulart. Em sua publicação, tais entidades defendem a tese de que sob este governo o país caminhava a passos largos para a "comunização". A apresentação, inclusive de uma data, para o deflagrar da revolução comunista, indica que este temor parecia realmente rondar a alta cúpula do empresariado paulista: "A Federação e o Centro das Indústrias do Estado de São Paulo, neste momento em que se consolida a recuperação cristã e democrática da Nação, congratulam-se com o povo brasileiro e com todas as forças civis e militares que repeliram, no movimento de 31 de março a ditadura comunista que se instalaria no país, com data marcada para o próximo mês" (Boletim Informativo, 758, 1964, p. 16).

O apoio das entidades industriais paulistas ao golpe e ao governo Castello Branco não poderia deixar de existir posto o fato de que grande número de seus dirigentes atuava nos organismos Instituto de Pesquisas e Estudos Sociais e Instituto Brasileiro de Ação Democrática, cuja ação conspiratória durante a gestão de João Goulart já foi apontada por diversos estudos (Bandeira, 1978; Dreifuss, 1981; Ramírez, 2005). A passagem a seguir, transcrita de discurso do presidente da FIESP e do CIESP, engenheiro Raphael Noschese, publicado no Boletim Informativo destas entidades, sugere que dentro da própria estrutura das mesmas, atuava-se em consonância com os preparativos golpistas dos militares.

A indústria de São Paulo pode, sem favor algum, orgulhar-se da atuação que os dirigentes do seu órgão de cúpula tiveram na vitória da revolução. Essa colaboração [...] foi um reflexo de um longo trabalho de colaboração promovido através dos anos e que culminou, num instante em que se tornava imperiosa uma ação militar, numa mobilização não só de consciências e de bons propósitos, mas de recursos indispensáveis ao desenvolvimento do esforço de guerra (Boletim Informativo, 760, 1964, p. 5).

Feitas estas considerações iniciais, bastante úteis para a compreensão dos fatos a seguir arrolados, resta apresentarmos os diálogos havidos entre as entidades representantes da indústria paulista e o governo Castello Branco em torno das políticas empregadas no combate à inflação. Nova- 
mente, como também havia feito logo no início do governo Goulart, a FIESP-CIESP apresenta a disposição da indústria em colaborar com as ações anti-inflacionárias do novo governo. "Vamos iniciar a grande batalha pelo combate à inflação, mas advertidos de que não poderá haver milagres. $\mathrm{O}$ empresariado brasileiro contra o qual pouco a pouco se estruturava e aperfeiçoava um terrível instrumento de destruição, está consciente das suas responsabilidades e da parte substancial que lhe caberá na tarefa de arrumar nossa casa" (Boletim Informativo, 759, 1964, p. 5).

Tais manifestações apenas reforçam a ideia de que a indústria já não coexistia com o processo inflacionário de forma a obter vantagens, como parecia ser o caso até o governo Kubitscheck. A aceleração da inflação já afetava diretamente as indústrias, modificando sua percepção deste fenômeno. Desta forma para os industriais o momento demandava um governo verdadeiramente comprometido com um programa anti-inflacionário. E o governo Castello Branco, tendo à frente a dupla Roberto Campos-Octávio Bulhões, apresenta-se com este espírito.

Logo que foi apresentado à nação, o Plano de Ação Econômica do Governo (PAEG) foi apoiado entusiasticamente pelas entidades industriais. Muito parecido com o Plano Trienal -também aprovado pelas indústrias paulistas- no que tange ao combate gradual à inflação visando à manutenção do desenvolvimento, o PAEG tinha como diferencial a defesa de um projeto de país que priorizava a iniciativa privada, em contraste com as ditas insinuações estatizantes, do projeto reformista contido no Trienal. Diante do novo plano, a indústria paulista se pronunciava demonstrando sua satisfação com o fato de o mesmo manter, no que concernia ao desenvolvimento econômico, do ponto de vista ideológico, uma tendência bastante favorável à iniciativa privada devido principalmente ao fato de delimitar de maneira nítida a participação governamental apenas sobre os setores de infraestrutura econômica e social (Boletim Informativo, 778, 1964).

O Jornal do Brasil, diário de maior circulação na época, noticia ao longo dos anos 1964 e 1965 em suas páginas diversos depoimentos de empresários ligados à FIESP e a Federação das Indústrias da Guanabara favoráveis às diretrizes do programa econômico do governo e de endosso à sua equipe econômica. ${ }^{5}$

${ }^{5}$ Na edição 94 do $1{ }^{\circ}$ Caderno podemos ler: "A Federação e o Centro das Indústrias do Estado de São Paulo darão todo o apoio às medidas de contenção de preços adotadas pelo Governo, e, nesse sentido distribuirão recomendação a todos os sindicatos" (Jornal do Brasil, 22 de abril de 1964, p. 10). No momento em que foi reeleito para comandar a federação paulista, Rafael Noschese reafirma o apoio ao governo "Noschese reafirma apoio ao governo, por dar condições para desenvolver a economia” (Jornal do Brasil, 22 de janeiro de 1965, p. 11). 
O que ainda preocupava aos industriais eram as possíveis majorações na carga tributária, impostas pela necessidade de conter os déficits públicos e a persistente contenção da liquidez de crédito ao setor privado. Neste aspecto, o PAEG apresentava metas e ações que preocupavam a indústria. $\mathrm{O}$ que não reduzia, entretanto, seu entusiasmo com as diretrizes do novo governo, como vemos na citação abaixo: "E agora, que o pesadelo pertence ao passado e a Nação pode debater, livre e desapaixonadamente, as questões que dizem respeito aos seus interesses, procurando encontrar, sem qualquer dirigismo ou coação, a solução que melhor pareça" (Boletim Informativo, 770, 1964, p. 7).

Através da análise dos encontros com autoridades federais, cujos assuntos tratados eram publicados no Boletim Informativo, é possível percebermos uma proximidade maior destas entidades com a alta cúpula do governo, comparado com o período de seu antecessor. Encontros com os ministros da Fazenda, do Planejamento, do Trabalho e da Indústria e Comércio eram muito frequentes. E até mesmo o presidente da República não tardava entre suas conferências com estas entidades. Tal percepção é confirmada pelas próprias entidades quanto afirmam que com o novo governo "restabelece-se, assim, em toda sua plenitude, um diálogo entre as forças da produção e o governo o qual estava interrompido lamentavelmente desde há muito tempo" (Boletim Informativo, 762, 1964, p. 4).

$\mathrm{O}$ assunto mais tratado nestes encontros referia-se à carência de crédito ao setor industrial, proporcionado pela forte restrição ao mesmo, fruto do programa anti-inflacionário do governo. Nestes diálogos, a indústria, que por um lado queixava-se do excesso de aperto, reconhecia a sua indispensabilidade para a contenção da inflação. Enquanto o governo, respaldado por enorme aceitação junto às elites industriais, se sentia confortável em manter o arrocho, o presidente da FIESP-CIESP, Raphael Noschese afirmava em discurso transcrito no Boletim Informativo, 783, de 7 de outubro de 1964, que a indústria paulista se mostrava preocupada com o prazo razoavelmente curto no qual se pretendia obter uma considerável estabilidade de preços. Para o industrial, esse prazo demandava tratamento de choque no combate à inflação, o que poderia pôr em risco a continuidade do desenvolvimento econômico. Duas semanas depois, o mesmo Boletim publicava pronunciamento do líder industrial afirmando estar em acordo com a tese do governo de que a expansão do crédito, através do Banco do Brasil, seria um dos principais pontos a serem controlados e examinados com o máximo de cautela, como um dos principais instrumentos para o adequado controle da inflação. Ressalvava o industrial, entretanto, a indispensabilidade deste mesmo crédito para o aumento da produção industrial. Esquecer este último aspecto, dizia para os responsáveis pelo controle da política creditícia do Banco do Brasil, poderia pôr em risco a 
própria indústria nacional (Boletim Informativo, 785, 1964). Claramente, em discurso publicado em 18 de novembro do mesmo ano, o presidente das entidades é ainda mais condescendente com o governo federal. A compreensão do industrial com as dificuldades advindas do clima inflacionário o leva a afirmar estarem as entidades que dirige, em pleno acordo de que na primeira fase de implantação do plano estabilizador, "o crédito em termos reais deva ser restringido, para que se absorva os possíveis excessos de pagamentos existentes" (Boletim Informativo, 789, 1964, p. 7). Diante de tamanha flexibilidade mostrada no discurso empresarial não poderia ser outra a ação do governo, que realmente se mostrava comprometido em conter a aceleração inflacionária, que não o de manter o aperto. O próprio Boletim Informativo publicava em 21 de outubro de 1964 o pronunciamento do presidente do Banco do Brasil, em recente encontro com a diretoria destas entidades deixando claro que a política governamental se colocava "no sentido de não financiar, de forma alguma, o $13^{\circ}$ mês salarial". Entendia o governo, segundo o que seu representante ali afirmava, que se este tivesse que emitir para financiar o décimo terceiro mês de salário estaria em perigo toda a política oficial de combate à inflação (Boletim Informativo, 785,1964, p. 14).

Em discursos tanto os ministros da área econômica, como o próprio presidente da república chegaram a solicitar aos empresários que revissem suas margens de lucro consideradas altas, para que os preços pudessem ser minorados. Diante de pronunciamento neste sentido realizado em fevereiro de 1965 por Castello Branco, solicitando literalmente que "a indústria lucre menos", as entidades empresariais de São Paulo e Guanabara respondem dizendo que apesar de acharem difícil tal contenção, recebem bem o pedido do presidente, destacando que o apoiam (Jornal do Brasil, 10 de fevereiro de 1965 , p. 9).

Mesmo diante de uma política menos gradualista do que julgavam conveniente, as entidades industriais paulistas continuavam exaltando as ações do governo Castello Branco. É possível compreendermos parte deste apoio entusiasta quando contrastamos a política salarial do atual governo com o período Goulart. Enquanto, naqueles anos, na publicação semanal das entidades industriais paulista, somavam-se notas e comentários sobre os excessivos reajustes salariais e ampliação de benefícios sociais, durante a gestão militar as únicas notas publicadas a este respeito resumem-se na divulgação dos seguintes "exigências" governamentais: "Examinou ainda o Ministro da Fazenda o problema dos aumentos salariais. Encareceu toda a cooperação da indústria com o governo, no sentido de evitar revisões salariais acima das preconizadas pelo Conselho Nacional de Política Salarial” (Boletim Informativo, 785, 1964, p. 16). 
Como já discutido aqui, os dados referentes ao período do PAEG não deixam dúvidas de que o maior êxito das políticas contracionistas de então se alcançou no arrocho salarial. Não poderia ser outra a reação industrial, se não a de apoio às mesmas, posto que grande parte de suas críticas ao governo Goulart tratavam exatamente de sua anuência a reajustes salariais acima da ampliação do custo de vida. De resto, restava à indústria utilizar seus caminhos de interlocução junto ao governo para reduzir ao menor tempo possível a duração das políticas anti-inflacionárias com efeitos negativos sobre a produção. Neste sentido, apelava insistentemente aos membros da área econômica do governo para que a fase aguda de tratamento de choque no combate à inflação não ultrapassasse 1964. Esperava a indústria que a partir de 1965, o governo cuidasse de seguir uma política de incentivos à capitalização e ao desenvolvimento industrial (Boletim Informativo, 789, 1964).

Em meados de 1965, a despeito de terem sido contidos os principais focos inflacionários, quais sejam, os altos déficits públicos financiados por emissões e a política salarial de grandes reajustes reais, a inflação não se reduzia aos índices previstos pelo governo. Duas teses divergentes começavam a ser produzidas pelo governo e pela indústria, como é possível notar nas entrelinhas de sua publicação semanal. Por parte dos principais ministros do governo, disseminava-se a tese de que a baixa produtividade da indústria nacional, constituída sobre forte proteção pública e subsidiada pelo Estado, aliada à política especulativa de industriais interessados em manter lucros extraordinários, impedia a inflação de reduzir-se substancialmente. Por seu turno, os industriais refutavam, como não poderia ser diferente, esta hipótese e começavam a esboçar sua visão de que grande parte da rigidez inflacionária devia-se ao seu componente de custos ignorado pela política oficial. Esta tese tem respaldo em parte da literatura que trata do período, que considera que o PAEG não se preocupou com o componente de custos da inflação, contribuindo inclusive, por meio do aumento da escassez e, consequente, encarecimento do crédito para seu acirramento (Martone, 1975). As razões destes aumentos de custo deviam-se, segundo os industriais, a três fatores principais: as variações cambiais encarecendo as matérias-primas importadas, a escassez de crédito que encarecia o capital, e os reajustes de tarifas públicas -a chamada inflação corretiva- que também majoravam os custos industriais. Em discurso publicado em janeiro de 1965, o presidente Raphael Noschese já destacava a imposição de reajustes de preços devido à alta nos custos. Para a FIESP "a política de créditos às empresas dever[i]á ser suficientemente controlada para impedir os excessos de inflação de procura, mas suficientemente realista para adaptar-se à inflação de custo" (Boletim Informativo, 797, 1965, p. 
3), o câmbio deveria ser estabilizado em nível realista e a inflação corretiva ser reduzida o mais ligeiramente possível.

O governo, por sua vez, visando controlar os reajustes de preços realizados pelas empresas, sanciona, por meio de Portaria Interministerial de número 71, a criação do Conselho Nacional para a Estabilização dos Preços, organismo responsável por oferecer uma série de benefícios fiscais às empresas signatárias. Como contrapartida, estas empresas deveriam manter os reajustes de seus preços dentro de certas taxas pré-estipuladas. Dentre os benefícios, alguns constituíam velha demanda dos industriais, como a possibilidade de revisão de seus capitais sociais corroídos pela inflação, livre de tributação. Os industriais queixavam-se que o capital nominal de suas empresas encontrava-se defasado, mas que a simples correção de seus valores para números realistas acarretaria em ônus tributário, seguindo as leis vigentes. A Portaria 71 possibilitava aos seus signatários realizar tal correção livre de impostos. Ainda propiciava descontos no Imposto de Renda e redução da exigência de Letras de Importação. Tal portaria, mesmo criticada em alguns pontos como na sua excessiva rigidez para conceder reajustes excepcionais de preços das empresas com grandes majorações de custos, foi fortemente encampada pela indústria, como fica claro na nota seguinte: "As entidades de classe, tendo à frente a Federação das Indústrias, não tiveram dúvidas em recomendar aos seus associados a conveniência de se adaptar à referida portaria, embora proclamando a existência de particularidades peculiares a muitas empresas que não podem deixar de ser consideradas pelas autoridades" (Boletim Informativo, 813,1965 , p. 4).

Os resultados da adaptação à referida portaria logo seriam percebidos pelos empresários. As reclamações quanto às dificuldades em aumentar os preços seguindo as ampliações nos custos detectadas, começaram a tomar as páginas de sua publicação semanal. Nem diante destas dificuldades, o apoio das indústrias às diretrizes gerais do governo esfriava. Lia-se nos dias iniciais de 1966, no Boletim Informativo: "O ano que se finda, a despeito de contrariedades e aflições, foi marcado, ao longo dos doze meses, pela primeira das condições para o êxito de qualquer empreendimento: a segurança” (p. 7). Tal sintonia, entretanto, não deve ser vista como total aceitação das políticas governamentais, mas sim como uma percepção de que com o regime militar a posição do empresariado era mais favorável. Claramente os industriais viam o governo de então como o "seu" governo, e mesmo diante de políticas que considerassem inadequadas, acreditavam que seria possível encontrar pontos comuns por meio do diálogo. É esta a síntese que podemos realizar de uma série de excertos publicados tanto no boletim oficial da entidade paulista quanto no Jornal do Brasil. Neles vemos diversas críticas pontuais a uma ou outra política do governo, sempre 
expressas por meio de telegramas ou memorandos enviados aos ministros ou até ao presidente, o que demonstra disposição ao diálogo. Críticas e ressalvas, como as diante do "excessivo arrocho creditício", ou a "pouca flexibilidade" no controle de preços realizado pela Comissão Nacional de Estímulos à Estabilização de Preços, eram expressas diretamente aos ministros ou diretores responsáveis em encontros realizados nas entidades empresariais, em Brasília ou em eventos comuns. Condenações mais severas ao governo e à sua política econômica, como as que começavam a ser realizadas por setores da sociedade civil, e por figuras públicas como Carlos Lacerda, não eram endossadas pela FIESP. Um exemplo desta postura ocorreu em 1966, quando entidades que apoiaram o golpe de 1964, organizando a Marcha da Família com Deus pela Liberdade, organizam a Marcha do Silêncio de teor crítico ás medidas adotadas pelo governo Castello Branco. A FIESP, então, divulgou nota à imprensa afirmando acreditar na capacidade dos poderes públicos em equacionar os problemas conjunturais e reafirmando sua "confiança e solidariedade ao Presidente da República" (Jornal do Brasil, 18 de março de 1966, p. 3).

Outra faceta da política anti-inflacionária do governo Castello Branco que afetava diretamente aos industriais correspondia à reforma tributária. Defendida ainda durante a gestão Goulart como uma de suas reformas de base, foi fortemente combatida pela indústria por seu viés "aumentista", como se afirmava. A indústria defendia uma reforma que gerasse maior eficiência arrecadatória, ao invés de simplesmente ampliar as alíquotas. Diante do novo contexto, expresso na vitória da "revolução" a opinião industrial se flexibiliza. A indústria continua defendendo a reforma da máquina arrecadadora, mas "entende" as "necessidades" do governo: "como a máquina arrecadadora não funciona como devia, como não se conseguiu ainda embutir no ânimo de todos a noção de que se deve pagar algo ao governo em troca da segurança e dos serviços que presta, o jeito é suportarmos esses gravames para evitar-se que surja o colapso total na ordem pública" (Boletim Informativo, 832, 1965, p. 4).

Novamente fica clara a colaboração industrial para com o governo Castello Branco. Mais uma vez, não se pode afirmar que os industriais tenham abdicado de defender seus interesses imediatos diante desta colaboração, mas sempre que o faziam deixavam claro que tal atitude não comprometia o apoio incondicional às políticas do governo que eles mesmos ajudaram a alçar ao poder, e que no limite representava seus interesses ideológicos. Mesmo a questão referente à escassez de crédito, que tanto atormentou os industriais, constando de praticamente todas as suas reuniões ordinárias como tema central, foi tratada em alto nível com os membros do governo. Este, em diálogo aberto com os industriais, mantinha firme sua política anti-inflacionária, sem, no entanto, deixar de oferecer contrapartidas à co- 
laboração industrial. Não foram poucos os elogios publicados no Boletim Informativo quanto às tentativas de se reduzir o problema do crédito, seja por meio da ampliação do Financiamento a Máquinas e Equipamentos, do Banco Nacional de Desenvolvimento Econômico e Social, ou de incentivos à solidificação de um mercado de capitais, entre outras ações sempre subordinadas à política estabilizadora.

Já nos meses finais do governo Castello Branco, entretanto, percebe-se o início de um descontentamento maior por parte das entidades industriais frente a certo enrijecimento do diálogo com os ministros Campos e $\mathrm{Bu}-$ lhões. Estes, especialmente Octávio Bulhões, como já foi destacado aqui, eram relativamente alinhados à corrente neoliberal de atuação estatal. Sua defesa da livre concorrência internacional refletida na defesa da redução do protecionismo alfandegário praticado no Brasil começava a se chocar com o projeto industrial. Na visão dos ministros, a indústria brasileira necessitava de um forte choque de produtividade, o que na visão industrial era obstaculizado pelo atraso das próprias instituições públicas e da infraestrutura nacional. Abrir a economia naquele momento poderia representar o aniquilamento do projeto industrial. Na citação abaixo é possível notar-se com clareza a interpretação dos industriais do quadro que parecia se construir nos meses finais da gestão destes ministros:

Esse novo decreto-lei [núm. 63, 21 de novembro de 1966] que reduz linearmente as alíquotas do imposto de importação e as medidas anteriores de diminuição tarifária revelam a predominância, no momento, de duas inquietantes tendências na solução da problemática brasileira: nova mudança dos "centros de decisão da política econômica" do setor interno para o internacional e reorientação dos padrões de crescimento econômico nacional, baseados no dinamismo do setor industrial interno, para os da agricultura de exportação e do comércio de importação (Boletim Informativo, 908, 1967, p. 5).

Os industriais percebiam o fortalecimento da corrente oposta ao "estatismo-socializante" que combatiam no governo Goulart, qual seja, o liberalismo-"internacionalizante", tão prejudicial ao seu projeto quanto a primeira. Não por outra razão haviam sido tão bem recebidas nas entidades industriais as palavras de um dos primeiros discursos de Castello Branco ao deixar clara a posição política de seu governo. Sobre este discurso, comentava o editorial da publicação dos empresários:

Os conceitos emitidos por Vossa Excelência, particularmente situando como do centro o novo governo da República, sem pender para o reacionarismo da direita nem para a esquerda subversiva, voltado para uma ideologia inspirada na justiça social, nos preceitos de uma democracia representativa, na necessidade de ativar o 
desenvolvimento nacional com o estímulo à livre empresa, revelam o equilíbrio do seu governo e as ideias sadias que o inspiram (Boletim Informativo, 771, 1964, p. 6).

Neste período (1966-1967) começam a aparecer na imprensa sinais de uma relação mais tensa entre os industriais e à equipe econômica do governo. As divergências podem ser resumidas em cinco pontos: demanda por maior participação das entidades na formulação da política econômica; melhor definição das áreas de atuação do Estado e da livre-empresa; redução da carga tributária; reformulação da política de preços da Conselho Nacional para a Estabilização dos Preços, e adoção de política cambial e tarifária que preservasse e fortalecesse a classe empresarial nacional. Tais pontos foram sintetizados em estudo publicado pela imprensa e creditado à FIESP e à Confederação Nacional das Indústrias (Jornal do Brasil, ed. 232, 2 de outubro de 1966 , p. 21).

$\mathrm{O}$ aumento da tensão entre os industriais e a equipe econômica do governo deixa nítido que o apoio empresarial ao regime militar não era incondicional, mas dependia do alinhamento da política econômica ao seu projeto enquanto classe. A ascensão do governo golpista foi apoiada entusiasticamente pelos empresários, pois representava uma vitória mais ampla, contra o que consideravam graves ameaças à propriedade privada e ao próprio regime do capital. Uma vez livre dos riscos à ordem capitalista, o empresariado pôde voltar a ordem do dia e exercer fortemente sua influência nas instâncias de governo de forma a ver atendidos seus interesses imediatos e suas demandas estratégicas. Desta forma, parece claro que, em finais de 1967, a condução da política econômica pela dupla Campos-Bulhões entrou em linha de choque com as ideias do setor industrial. O clima era promissor, e faltava apenas que os incentivos se tornassem mais claros para que uma forte onda de investimentos e contratações libertassem a economia das amarras impostas primeiro pela crise, e agora pelas restrições econômicas.

Se não é possível afirmar que foram os industriais os principais responsáveis pela guinada acontecida, com a posse do general Arthur da Costa e Silva na presidência da república e a escolha de Antonio Delfim Netto para ocupar o Ministério da Fazenda, também é temerário não levar em conta o peso de sua influência. $\mathrm{O}$ fato é que as teses que começavam a constar dos pronunciamentos industriais foram tornadas centrais na política econômica do novo governo. $\mathrm{O}$ combate à inflação passou a orientar-se para seu componente de custos. $\mathrm{O}$ crédito foi fortemente aquecido. Os investimentos estatais em infraestrutura foram retomados. A tão temida abertura externa foi freada e esquecida. Por fim, a economia voltou a alcançar altas taxas de crescimento e a inflação foi finalmente posta sobre controle. Não consta do escopo deste trabalho apontar a relação dos industriais com o 
novo governo de Costa e Silva. Mas parece claro, que esta classe teve uma relação muito mais interativa com o regime militar -ao menos em seu início- que com o seu antecessor João Goulart, e que tal relação tem papel bastante importante para explicar o sucesso destes governos em estancar a crise e permitir a retomada do crescimento.

No gráfico 1 podemos visualizar o comportamento da taxa de inflação, medida pelo índice geral de preços, calculado pela Fundação Getúlio Vargas e do produto interno bruto. Nele fica nítido que já a partir de 1965 a inflação entra em compasso de queda, e no ano seguinte o produto volta a crescer a taxas elevadas. $\mathrm{O}$ auge da crise claramente estava superado.

É consenso na literatura econômica que o PAEG e as reformas do governo Castello Branco foram cruciais para a retomada do crescimento da economia, no período que ficou conhecido como milagre econômico. Neste trabalho procuramos demonstrar que diferente do que sugere parte desta literatura, tais políticas não possuíam caráter meramente técnico, mas encontravam-se entremeadas em posições ideológicas, e foram construídas, apoiadas e ou reformuladas em meio a denso diálogo com as classes e frações de classes com maior poder político e econômico. Neste trabalho destacamos o papel do empresariado industrial, outros podem ser realizados visando a compreender o peso da influência de setores como financeiros e agrários no período. $\mathrm{O}$ ponto fulcral consiste em compreender que o Estado não é, como parece sugerir parte dos economistas, um ente isolado e independente, mas sim um espaço de relações e conflitos entre agentes altamente interessados.

\section{CONSIDERAÇÕES FINAIS}

Os textos e documentos da época não deixam dúvidas quanto à decisiva participação do empresariado industrial no golpe que retirou do poder o presidente João Goulart. Sendo assim, não deve ser visto com nenhuma surpresa a grande sintonia entre esta classe e o governo que substituiu ao líder deposto. Neste trabalho foi demonstrado, por meio do discurso empresarial publicado no principal meio de comunicação da sua entidade mais representativa, o que significou esta sintonia para os desdobramentos da economia do país. O governo Castello Branco, e seu plano de contenção inflacionária, o PAEG, foram analisados a partir do ponto de vista empresarial, relativizando assim o papel do Estado, sempre protagonista nas produções da literatura econômica tradicional. Por meio da análise do discurso, já consagrada em outros trabalhos citados ao longo do texto,

foi possível perceber que o apoio fornecido pelo empresariado ao novo governo, foi fundamental para legitimar e respaldar suas ações no campo 


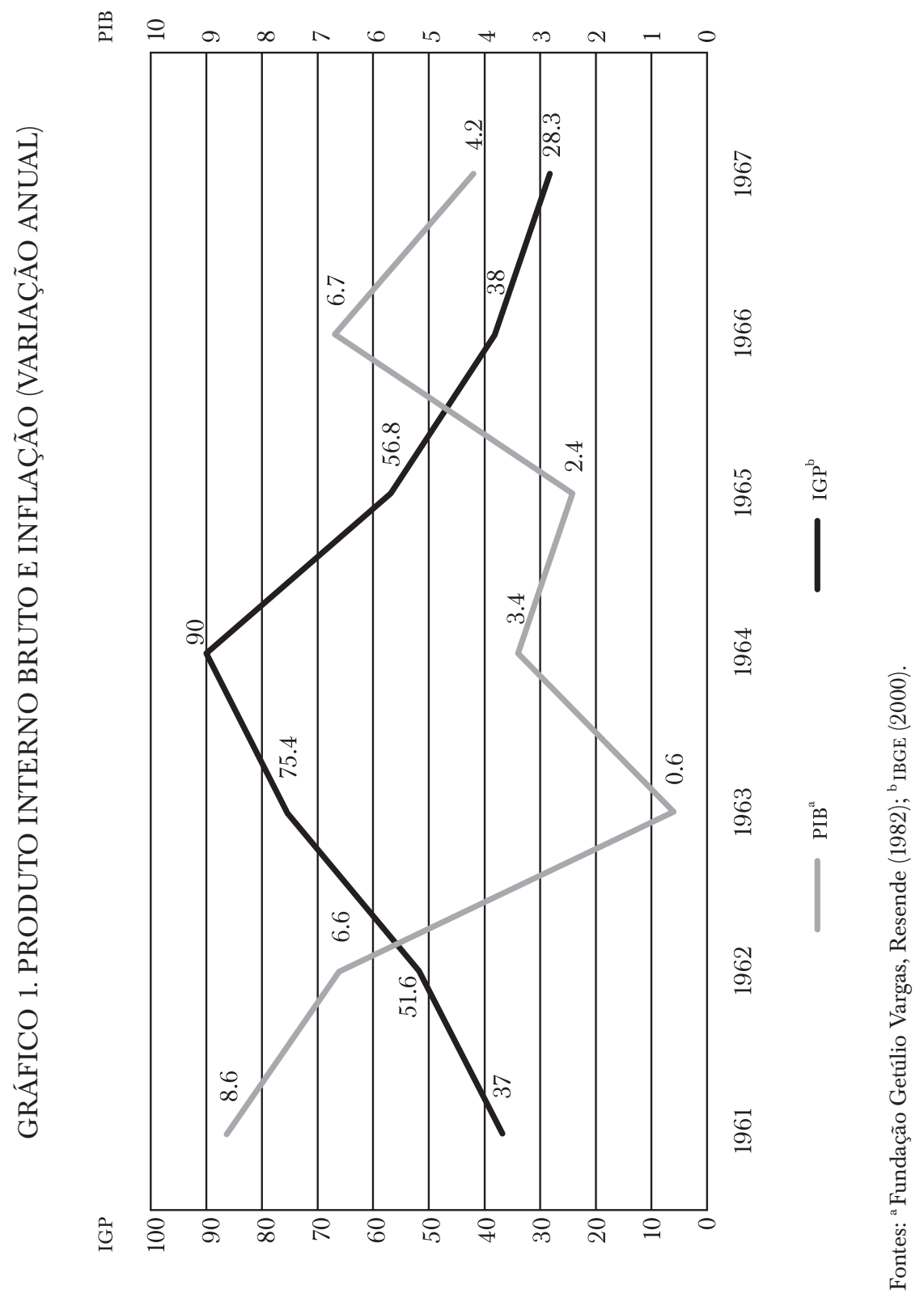


econômico. Esta legitimidade era fundamental, tendo em vista que o processo de combate à inflação imporia demasiados custos a todos os setores da sociedade, inclusive ao empresariado. A aceitação destes custos por parte do empresariado, mesmo quando ultrapassavam suas previsões mais pessimistas, como no caso da contração no crédito, foi fundamental para o êxito do programa.

Ao longo do período estudado, o discurso empresarial sempre se manteve sobre um eixo de respaldo ao governo e otimismo quando às suas ações econômicas, pilares estes que faltaram ao longo de praticamente todo o governo Goulart. A proximidade entre esta classe e o governo militar caracteriza a própria coincidência de objetivos entre ambos, diferente do caso do governo anterior cujo projeto de país tomava rumos antagônicos à ideologia empresarial, em fase de consolidação. Neste sentido, é possível afirmar que o governo Castello Branco, ao marchar na defesa da propriedade privada, do desenvolvimento econômico e industrial e especialmente na contenção dos excessos trabalhistas e sindicais, colocava-se na mesma trincheira do empresariado. Esta é a razão maior da completa legitimidade oferecida por estes últimos ao referido governo. Aceitar alguns custos, por ora excessivos, seria, assim, o preço a pagar pela segurança e o respaldo público ao livre desenvolvimento do projeto industrial. Uma vez contidos os excessos inflacionários e a crise política e econômica, o segundo governo militar, tendo à frente da área econômica o ministro paulista, Antonio Delfim Netto, levaria à concretização plena do desenvolvimento brasileiro nos moldes do programa industrial.

\section{LISTA DE REFERÊNCIAS}

BAER, W. (1996). A economia brasileira. São Paulo: Nobel.

BAndeIRA, M. (1978). O governo João Goulart: as lutas sociais no Brasil (3a. ed.). Rio de Janeiro: Civilização Brasileira.

BiAnchi, Á. (2010). Um ministério dos industriais: a Federação das Indústrias do Estado de São Paulo na crise das décadas de 1980 e 1990. Campinas: Editora Unicamp.

Boletim Informativo do Centro das Indústrias do Estado de São Paulo/Federação das Indústrias do Estado de São Paulo [Boletim Informativo] (1961-1967). São Paulo: Centro das Indústrias do Estado de São Paulo-Federação das Indústrias do Estado de São Paulo. Semanal.

Brasil (1964). Ministério do Planejamento e Coordenação Econômica. Em Plano de Ação Econômica do Governo: 1964-1966. Rio de Janeiro: s. n.

Cano, W. (1981). As raízes da concentração industrial em São Paulo (2a. ed.). Rio de Janeiro:

Difel. 
Colistete, R. P. (2009). Salários, produtividade e lucros na indústria brasileira, 1945-1978. Revista de Economía Política, 29(4), 386-405. DOI: 10.1590/S0101-31572009000400005

Dean, W. (1991). A industrialização em São Paulo (1880-1945) (4a. ed.). Rio de Janeiro: Bertrand Brasil.

Dreifuss, R. A. (1981). 1964: a conquista do Estado: ação política, poder e golpe de classe (2a. ed.). Petrópolis: Vozes.

Hermann, J. (2005). Reformas, endividamento externo e o "milagre" econômico (1964-1973). Em F. Giambiagi et al., Economia brasileira contemporânea (1945-2004) (pp. 69-92). Rio de Janeiro: Elsevier.

Hoffmann, R. (1978). Tendências da Distribuição da Renda no Brasil e suas Relações com o Desenvolvimento Econômico. Em R. Tolipan e A. C. Tinelli, A Controvérsia da Distribuição de Renda no Brasil, Zahar Editores, Rio de Janeiro.

Instituto Brasileiro de Geografia e Estatística/Sistema de Contas Nacionais [IBGE] (2000). Estatísticas do Século XX. Rio de Janeiro: Instituto Brasileiro de Geografia e Estatística/Centro de Documentação e Disseminação de Informações.

Instituto Brasileiro de Geografia e Estatística [IBGE] (2015). Sistema IBGE de Recuperação Automática. Pesquisa Industrial Anual. Tabela 2221, Dados gerais das indústrias extrativas e de transformação segundo classes e gêneros de indústria. Recuperado de http://www.sidra.ibge.gov.br/bda/acervo/acervo9.asp? $=\mathrm{e} \& \mathrm{p}=\mathrm{PI} \& \mathrm{z}=\mathrm{t} \& \mathrm{o}=22$

IPEADATA (2015). Produto interno bruto [PIB] -indústria- referência 2000. Recuperado de www.ipeadata.gov.br

Jornal do Brasil. (1964-1967). Rio de Janeiro. Recuperado de http://bndigital.bn.br/ hemeroteca-digital/

LeOPOLDI, M. A. P. (2000). Política de interesses na industrialização brasileira: as associações industriais, a política econômica e o Estado. São Paulo: Paz e Terra.

Lopreato, F. (2011). Caminhos da política fiscal no Brasil (Tese de livre docência). Campinas: Universidade Estadual de Campinas.

LuCinda, C. R. e ARvate, P. R. (julho-setembro, 2005). Uma nova versão sobre a oferta de moeda no Plano de Ação Econômica do Governo (PAEG). Estudos Econômicos, 35(3), 391-431.

MADI, M. A. (1985). A vanguarda do pensamento conservador: um estudo sobre as ideias econômicas de Roberto Campos no período 1950-1964 (Dissertação de mestrado). Campinas: Universidade Estadual de Campinas.

Martone, C. L. (1975). Análise do Plano de Ação Econômica do Governo (PAEG) (1964-1966) (pp. 69-90). Em B. M. LAFER, Planejamento no Brasil (3a. ed.). São Paulo: Perspectiva.

Moraes, R. (2012). O governo João Goulart e o empresariado industrial: uma abordagem alternativa da história econômica do período de 1961 a 1964. Em 40 Encontro Nacional de Economia da ANPEC, 2012, Ipojuca: Pernambuco.

Ramírez, H. (2005). Os Institutos de Estudos Econômicos de Organizações Empresariais e sua relação com o Estado em perspectiva comparada: A Argentina e Brasil, 1961-1996 (Tese de doutorado). Universidade Federal do Rio Grande do Sul, Porto Alegre. 
Resende, A. L. (dezembro, 1982). A política brasileira de estabilização 1963-1968. Pesquisa e Planejamento Econômico, 12(3), 757-806.

REsende, A. L. (1990). Estabilização e reforma: 1964-1967. Em M. DE P. AbREU (org.), A ordem do progresso: cem anos de política econômica republicana 1889-1989. Rio de Janeiro: Campus.

Santos, M. H. P. Dos. (2000). Roberto de Oliveira Campos: homem de ação do governo Castello Branco. São Paulo em Perspectiva, 14(2), 112-121.

Saretta, F. (janeiro-abril, 2001). Octávio de Gouveia Bulhões. Estudos Avançados, 15(41), 111-125.

SARetTA, F. (2010). A reação da Confederação Nacional da Indústria ao Plano de Estabilzação Monetária. II Congresso Latinoamericano de Historia Economica, CLADHE, 2010, Cidade do México (pp. 1-23). Simpósio La Industrialización por Sustitución de Importaciones y la Apertura Económica en América Latina. Estudios Sectoriales y Tramas Productivas. Cidade do Mexico.

Sochaczewski, A. C. (1993). Desenvolvimento econômico e financeiro do Brasil 1952-1968. São Paulo: Trajetória Cultural.

Viana Filho, L. (1975). O governo Castelo Branco (2a. ed.). Rio de Janeiro: José Olympio.

\section{OUTRAS FONTES}

\section{Bibliografia}

Castello, H. DE A. (1965). Discursos 1964. Brasília: Secretária de Imprensa.

Castello, H. DE A. (1979). Castello Branco, 1965-1967. Em Brasil, Presidente. Mensagens Presidenciais 1965-1979 (pp. 35-82). Brasília: Centro de Documentação e Informação-Coordenação de Publicações. 